\title{
A prospective study of 39 patients with trigeminal neuralgia treated with percutaneous balloon compression
}

\author{
Wuilker Knoner Campos' ${ }^{1}$ Marcelo N. Linhares²
}

\begin{abstract}
Objective: Trigeminal neuralgia is the most common facial pain. It may be treated with percutaneous balloon compression (PBC), which is considered to be a safe and efficient procedure. The purpose of this study was to review our results with PBC and to assess the factors influencing the outcome. Method: A multivariate analysis was used to study 39 patients during a 50-month postoperative period. Results: There was predominance of the female gender (54\%), the right side of the face (84\%) and V2V3 roots of trigeminal nerve (33\%). The mean age was 62.3 years. No major complications or deaths occurred. Among all variables, postoperative hypoesthesia was the single prognostic factor capable of positively influencing the results $(p=0.02)$. Most patients (80\%) were pain-free after 50 months with a $90 \%$ satisfaction rate. Conclusion: PBC was a safe procedure with low morbidity, no mortality, high approval ratings, and was an important improving on patients' quality of life.
\end{abstract}

Key words: trigeminal neuralgia, facial hypoesthesia, percutaneous balloon compression, trigeminal nerve, facial neuralgia.

Estudo prospectivo de 39 pacientes com neuralgia do trigêmeo tratados com compressão por balão percutâneo

\section{RESUMO}

Objetivo: A neuralgia do trigêmeo é a dor facial mais comum. Ela pode ser tratada através da compressão percutânea com balão, que é considerado procedimento seguro e eficaz. A proposta deste estudo foi avaliar nossos resultados e os fatores que influenciariam o seguimento. Método: Foi utilizada análise multivariada para estudar 39 pacientes submetidos ao procedimento, com seguimento de 50 meses. Resultados: Houve predominância do sexo feminino (54\%), lado direito (84\%) e dos ramos V2V3 (33\%). A idade média foi de 62,3 anos. Não houve complicações maiores ou óbito. Dentre todas as variáveis, a única capaz de influenciar positivamente os resultados foi a hipoestesia pós-operatória $(p=0,02)$. A maioria dos pacientes $(80 \%)$ estava livre da dor após 50 meses de seguimento, com $90 \%$ de satisfação. Conclusão: Este procedimento foi considerado seguro, com baixa morbidade, sem mortalidade, com alta taxa de aprovação e representou melhora importante na qualidade de vida dos pacientes.

Palavras-chave: neuralgia do trigêmeo, hipoestesia facial, compressão percutânea com balão, nervo trigêmeo, neuralgia facial.

\section{Correspondence}

Wuilker Knoner Campos

Neuron, Instituto de Neurocirurgia

Rua Menino Deus 63 / sala 419

88020-210 Florianópolis SC - Brasil

E-mail: wuilker@yahoo.com.br

Received 24 June 2010

Received in final form 29 October 2010

Accepted 5 November 2010
Trigeminal neuralgia (TN) is the most common type of facial neuralgia with incidence of $26.8 / 100,000$ person-year ${ }^{1}$. It is considered to be one of the most painful conditions to affect patients ${ }^{2}$. It is charac- terized by paroxysmal, excruciating and unilateral pain attacking one or more of the trigeminal nerve roots. The diagnosis of TN is clinical and is based on the patient's history, such as the trigger zone and

${ }^{1} \mathrm{MD}$, Neuron, Institute of Neurosurgery, Florianópolis SC, Brazil. Division of Neurosurgery, Federal University of Santa Catarina, Florianópolis SC, Brazil; ${ }^{2} \mathrm{MD}$, PhD, Neuron, Institute of Neurosurgery, Florianópolis SC, Brazil; Division of Neurosurgery, Federal University of Santa Catarina, Florianópolis SC, Brazil. 
unilateral lancinating paroxysms followed by refractory periods, and the exclusion of other causes of facial pain. Despite progress in neuroscience, the exact cause of TN has not been fully explained ${ }^{2-4}$. Initially, the treatment for TN should be pharmacological, but when this fails or is limited by significant side effects, surgical options are indicated. The treatment should be tailored to each patient, and depends on the patient's age, trigeminal nerve division involved, medical comorbidities, surgeon's experience and the risks that the patient is willing to take. Percutaneous balloon compression (PBC), as first described by Mullan ${ }^{5}$ using a Fogarty embolectomy catheter to compress the ganglion and retrogasserian nerve, is a useful and minimally invasive technique with low risks and low morbidity ${ }^{6,7}$. The goals of this study are to review our results with $\mathrm{PBC}$ technique and to assess its side effects and the factors influencing the outcome.

\section{METHOD}

\section{Patient population}

In our series, 39 procedures were performed in $39 \mathrm{pa}-$ tients ( 21 women, 18 men) with TN from January 2000 to December 2004. Patients with electric shock-like, paroxysmal pain with no abnormalities in neurological examination and no pathological findings in MRI or CT scans were accepted as having primary trigeminal neuralgia. All procedures were performed by the same surgeon (MNL). The course of the disease ranged from 11 months to 20 years, and the patients' follow-up periods were up to 50 months. Procedures were performed as an outpatient surgery in the radiological suite or in the operating room, with patients being discharged home on the same day. Ethics committee of the hospital has approved this paper and the patients gave their informed consent.

\section{Patient database}

This is a prospective uncontrolled study. The demographic data were collected from patient records, and the follow-up was assessed by phone interviews. The analyzed variables were gender, age, duration of disease, previous surgical treatment, facial side involved, root(s) involved, previous dental procedures (root canal treatment or dental extraction), pain relief, and minor and major complications. TN pain was evaluated by the visual analogue scale (VAS), and the life-impact grade of the TN pain was evaluated using a quality of life impact scale (Graph 1): minimal (little interference with daily activity), medium (high interference, but tolerable) and high impact (total interference, the patient cannot complete daily activities). Questions were also posed to determine whether there was a relationship between masticatory difficulties related to TN and weight loss, both of which

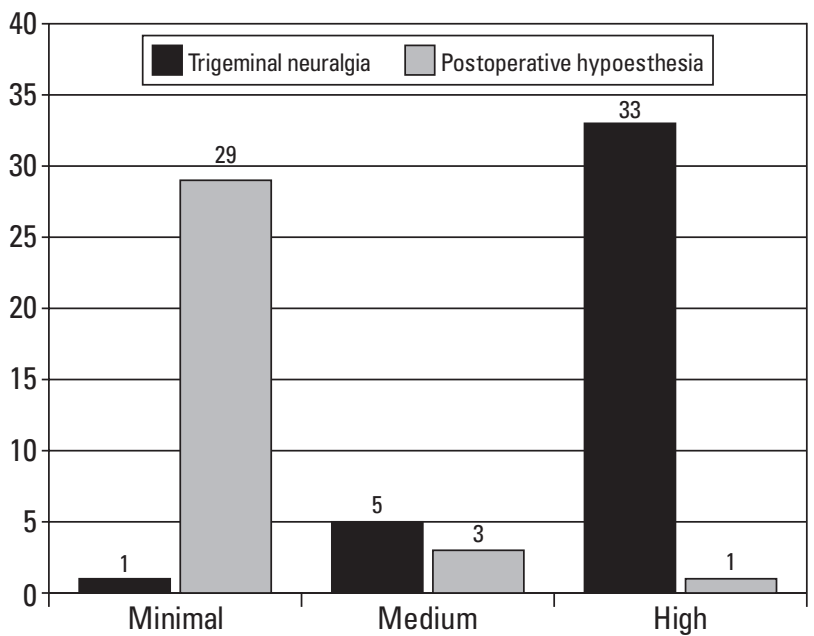

Graph 1. Life quality impact scale: trigeminal neuralgia versus postoperative hypoesthesia.

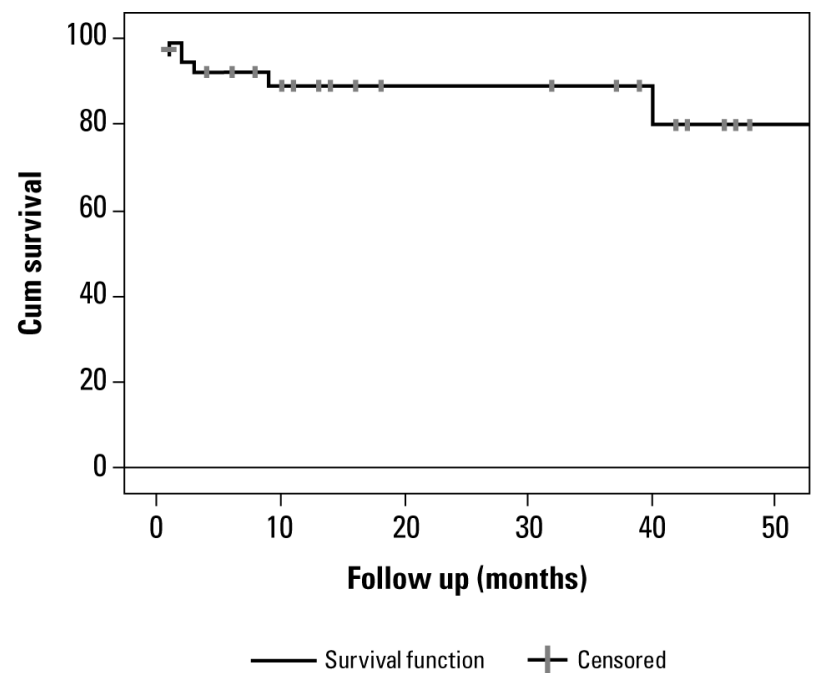

Graph 2. Kaplan-Meier survival curve: this graph shows the results of analysis of pain recurrence rate (Y-axis) for patients with TN treated with PBC during 50-month of follow-up (X-axis). The curve indicates that $80 \%$ of the patients are pain-free at 50 months after surgery without recurrence. Each tick mark represents the time one patient had pain recurrence showing the number remaining "at risk" at several points instead. Thus we can note a recurrence rate of $20 \%$ within up to 36 months.

were complaints made by TN patients. When prolonged (more than three months) postoperative hypoesthesia occurred, the life-impact grade of hypoesthesia was also evaluated using the quality of life impact scale and compared with the life-impact grade of the preoperative pain. The procedure satisfaction grade after $\mathrm{PBC}$ was evaluated using the following scale: bad, good and excellent.

\section{Surgical procedures}

Briefly, after general anesthesia, the surgeon placed a Tuohy needle in the retrogasserian portion of the tri- 
geminal nerve by freehand manipulation using an image intensifier in the lateral plane. After observing cerebrospinal fluid come out through the needle, the surgeon inserted a 4-French Fogarty catheter through the needle and then inflated the balloon with non-ionic contrast for one minute. The typical pear or bean shape showed that the balloon was in the appropriate position. Following completion of the compression, the balloon was deflated and withdrawn, and the patient was discharged after recovering from the anesthesia.

\section{Statistical analysis}

The cumulative probability of remaining pain-free at follow-up was calculated with the Kaplan-Meyer survival curve (Graph 2). A univariate analysis was performed (Table 1) comparing variable distribution between patients with surgically favorable results (no pain) and unfavorable results (recurrence or no pain relief) using Cox proportional hazard model analysis. All variables that presented $\mathrm{p}<0.20$ in the univariate analysis (Table 1 ) were included in the final multivariate analysis (Table 2) in order to establish independent correlations between such variables and the surgical results. The Fisher test was used to analyze the relationship between masticatory difficulty due to $\mathrm{TN}$ and weight loss. In the final analysis, $\mathrm{p}<0.05$ was considered statistically significant. The statistical analysis was performed using SPSS 12 software for Windows.

Table 1. Demographic database and univariate Cox proportional hazard model analysis.

\begin{tabular}{|c|c|c|c|c|c|c|}
\hline \multirow[b]{2}{*}{ Variables } & \multirow[b]{2}{*}{$\begin{array}{l}\text { All patients } \\
n=39(100 \%)\end{array}$} & \multicolumn{2}{|c|}{ Surgical results } & \multirow[b]{2}{*}{$\begin{array}{l}\text { Recurrence } \\
\text { hazard rate }\end{array}$} & \multirow[b]{2}{*}{$\begin{array}{c}95 \% \text { confidence } \\
\text { interval }\end{array}$} & \multirow[b]{2}{*}{$\mathrm{p}$} \\
\hline & & $\begin{array}{c}\text { Improved } \\
n=33(84.6 \%)\end{array}$ & $\begin{array}{l}\text { Recurrence } \\
n=6(15.4 \%)\end{array}$ & & & \\
\hline \multicolumn{7}{|l|}{ Sex } \\
\hline Masculine & $18(46)$ & $15(83.3)$ & $3(16.7)$ & 1.0 & & \\
\hline Feminine & $21(54)$ & $18(85.7)$ & $3(14.3)$ & 1.53 & $(0.29-7.95)$ & 0.61 \\
\hline \multicolumn{7}{|l|}{ Age } \\
\hline Mean (SD) & $62.3(12.5)$ & $61.7(12.7)$ & $63.5(12.5)$ & & & \\
\hline 60 years or less & $17(44)$ & $14(82.4)$ & $3(17.6)$ & 1.0 & & \\
\hline$>60$ years & $22(56)$ & $19(86.4)$ & $3(13.6)$ & 3.0 & $(0.44-20.47)$ & 0.26 \\
\hline \multicolumn{7}{|l|}{ Duration of the pain } \\
\hline Mean (SD) & $7.5(6.1)$ & $8.2(6.3)$ & $3.8(2.4)$ & & & \\
\hline 10 years or more & $12(31)$ & $12(100)$ & 0 & & & \\
\hline$<10$ years & $27(69)$ & $21(77.8)$ & $6(22.2)$ & No & No & 0.33 \\
\hline \multicolumn{7}{|c|}{ Previous surgical treatment } \\
\hline Yes & $8(20.5)$ & $5(62.5)$ & $3(37.5)$ & 1.0 & & \\
\hline No & $31(79.5)$ & $28(90.3)$ & $3(9.7)$ & 5.19 & $(0.86-31.04)$ & 0.07 \\
\hline \multicolumn{7}{|l|}{ Involved facial side } \\
\hline Right & $33(84.5)$ & $28(84.8)$ & $5(15.2)$ & 1.0 & & \\
\hline Left & $6(15.5)$ & $5(83.3)$ & $1(16.7)$ & 2.0 & $(0.21-19.28)$ & 0.55 \\
\hline \multicolumn{7}{|l|}{ Trigeminal nerve root } \\
\hline One root & $20(51)$ & $16(80)$ & $4(20)$ & 1.0 & & \\
\hline$>1$ root & $19(49)$ & $17(89.5)$ & $2(10.5)$ & 0.44 & $(0.79-2.47)$ & 0.34 \\
\hline \multicolumn{7}{|c|}{ Previous odontologic procedure* } \\
\hline No & $33(84.6)$ & $28(84.8)$ & $5(15.2)$ & 1.0 & & \\
\hline Yes & $6(15.4)$ & $5(83.3)$ & $1(16.7)$ & 2.16 & $(0.22-20.1)$ & 0.50 \\
\hline \multicolumn{7}{|l|}{ Pain relief } \\
\hline No immediate & $8(20.5)$ & $4(50)$ & $4(50)$ & 1.0 & & \\
\hline Immediate & $31(79.5)$ & $29(93.5)$ & $2(6.5)$ & 9.45 & $(1.67-53.45)$ & 0.01 \\
\hline \multicolumn{7}{|l|}{ Hypoesthesia } \\
\hline No & $6(15.5)$ & $3(50)$ & $3(50)$ & 1.0 & & \\
\hline Yes & $33(84.5)$ & $30(90.9)$ & $3(9.1)$ & 12.0 & $(1.98-73.8)$ & 0.007 \\
\hline \multicolumn{7}{|c|}{ Herpes simplex pos-operation } \\
\hline Yes & $17(43.6)$ & $14(82.4)$ & $3(17.6)$ & 1.0 & & \\
\hline No & $22(56.4)$ & 19 (86.4) & $3(13.6)$ & 0.65 & $(0.12-3.24)$ & 0.60 \\
\hline \multicolumn{7}{|l|}{ Complications } \\
\hline No & $20(51.3)$ & $17(85)$ & $3(15)$ & 1.0 & & \\
\hline Yes & $19(48.7)$ & $16(84.2)$ & $3(15.8)$ & 1.12 & $(0.22-5.65)$ & 0.88 \\
\hline
\end{tabular}

Variables with $p<0.20$ (bold). *Root canal treatment and dental extraction. 
Table 2. Final analysis: multivariate Cox proportional hazard model.

\begin{tabular}{|c|c|c|c|c|c|c|}
\hline \multirow[b]{2}{*}{ Variables } & \multirow[b]{2}{*}{$\begin{array}{l}\text { All patients } \\
n=39(100 \%)\end{array}$} & \multicolumn{2}{|c|}{ Surgical results } & \multirow[b]{2}{*}{$\begin{array}{l}\text { Recurrence } \\
\text { hazard rate }\end{array}$} & \multirow[b]{2}{*}{$\begin{array}{c}95 \% \text { confidence } \\
\text { interval }\end{array}$} & \multirow[b]{2}{*}{$\mathrm{p}$} \\
\hline & & $\begin{array}{c}\text { Improved } \\
n=33(84.6 \%)\end{array}$ & $\begin{array}{l}\text { Recurrence } \\
n=6(15.4 \%)\end{array}$ & & & \\
\hline \multicolumn{7}{|c|}{ Previous surgical treatment* } \\
\hline Yes & $8(20.5)$ & $5(62.5)$ & $3(37.5)$ & 1.0 & & \\
\hline No & $31(79.5)$ & $28(90.3)$ & $3(9.7)$ & 3.83 & $(0.43-33.92)$ & 0.22 \\
\hline \multicolumn{7}{|l|}{ Pain relief } \\
\hline No immediate & $8(20.5)$ & $4(50)$ & $4(50)$ & 1.0 & & \\
\hline Immediate & $31(79.5)$ & $29(93.5)$ & $2(6.5)$ & 1.99 & $(0.22-17.84)$ & 0.53 \\
\hline \multicolumn{7}{|l|}{ Hypoesthesia } \\
\hline No & $6(15.5)$ & $3(50)$ & $3(50)$ & 1.0 & & \\
\hline Yes & $33(84.5)$ & $30(90.9)$ & $3(9.1)$ & 22.0 & $(1.64-290.9)$ & $0.02^{* *}$ \\
\hline
\end{tabular}

*Root canal treatment and dental extraction; **Significant.

\section{RESULTS}

The right side was the most affected side (84\%). The V2V3 roots were affected in 13 patients (34\%), V2 root in 10 patients (26\%), V3 root in 8 patients (20\%), V1V2 roots in 6 patients (15\%), and V1 root in 2 patients (5\%). The factors associated with pain recurrence, demographic data and the univariate analysis are shown in Table 1. All patients classified the TN pain as a "very severe" using the VAS. Eight patients underwent previous surgical procedures including radiofrequency thermorhizotomy, cisternal injection of glycerol and microvascular decompression.

Postoperative complications included prolonged hypoesthesia in four patients, masticatory weakness in seven, loss of the corneal reflex without keratitis in one, gustatory dysfunction in two, and changes in lacrimation in three. In addition, one patient presented with transient abducens ophthalmoplegia and another presented with postoperative subarachnoid hemorrhage, with successful conservative treatment. There were no deaths, cerebral damage, or analgesia dolorosa. Postoperative hypoesthesia was the single prognostic factor capable of positively influencing the results $(p=0.02, H R=22)$. The result of the Fisher test, used to analyze the relationship between masticatory pain complaints and weight loss, was 0.65 . Thirty three patients $(84.6 \%)$ benefitted from $\mathrm{PBC}$ and six recurrences (15.4\%) occurred in a followup period of 50 months (Graph 2). After this time, when asked about their level of satisfaction with PBC the patients stated it was 'excellent' in 25 patients (64\%), 'good' in 10 patients (26\%) and 'bad' in 4 patients (10\%).

\section{DISCUSSION}

Despite the initial good control of TN with medical treatment, some patients may eventually fail. In previously published data, half of the patients were controlled by drugs without side effects, $25 \%$ were controlled but endured intolerable side effects and $25 \%$ were not controlled ${ }^{7}$. When drugs become ineffective or intolerable, the discussion on the appropriate surgical intervention, whether percutaneous or open, becomes important. There are well-known surgical options to treatment of TN: three percutaneous procedures (trigeminal percutaneous radiofrequency thermorhizotomy, retrogasserian glycerol injection and $\mathrm{PBC}$ ) and two open surgery (partial sensory rhizotomy and microvascular decompression $)^{7}$.

In our opinion, percutaneous procedures have a well established place for its safety, particularly in elderly patients. Microvascular decompression (MVD) has been preferred in younger patients due to its non-ablative nature. However, there are currently no clear guidelines for surgical treatment of $\mathrm{TN}^{7}$.

$\mathrm{PBC}$ is predicated on matching the time of balloon inflation with radiographic imaging and may be performed under general anesthesia, which is pain-free to the patient during the entire procedure and may add to the comfort level of the surgeon. In our cases, despite the old age of some patients (mean age of $62.3, \mathrm{SD}=12.5$ ), $\mathrm{PBC}$ has proven to be a safe procedure without mortality and with few complications, as expected according to large series published in the literature. The biological rationale for TN occurrence in the elder population has been explained by atherosclerotic changes to the arteries, resulting in prolongation and tortuosity of the vessels, thus possibly providing neurovascular contact. However the exact cause of TN remains unclear. When TN occurs in a young patient or when it is bilateral, the presence of demyelinating conditions such as multiple sclerosis should be investigated ${ }^{5,8-23}$.

The goal of $\mathrm{PBC}$ is to injure the myelinated fibers that mediate the "trigger" for the lancinating pain of trigeminal neuralgia. The corneal reflex is mediated by unmy- 
elinated fibers and when they are injured, there is loss of the corneal reflex ${ }^{14}$. Hypesthesia, paresthesia, and hypoesthesia are known consequences of all percutaneous procedures directed at the trigeminal ganglion. In our series (Table 2), postoperative hypoesthesia was the single prognostic factor capable of positively influencing the results $(\mathrm{p}=0.02, \mathrm{HR}=22)$. About $33(84.5 \%)$ of the patients had mild to moderate postoperative hemifacial numbness (hypoesthesia) that gradually diminished with time and was well tolerated. This transient hypoesthesia usually can be considered as a side effect of $\mathrm{PBC}^{10,23}$. However, four patients had permanent hypoesthesia and, in these cases, hypoesthesia is considered to be a complication. These patients did not consider the procedure satisfactory because of their difficulty adapting to the hypoesthesia. On the other hand, when the impact of preoperative TN pain was compared with postoperative hypoesthesia on quality of life, it was observed a better tolerance by patients for postoperative hypoesthesia than for TN pain (Graph 1). Most patients (90\%) considered the procedure satisfactory, despite the side effects and complications.

The impact on the quality of life of the TN patients is very important, and one third of patients in the present study presented with TN pain for more than ten years. Sometimes the TN pain may be confused with dental pain leading the patient to undergo unnecessary dental procedures. In the present study, 12 (31\%) patients had visited the dentist and six (15.4\%) patients had undergone previous unnecessary dental procedures (root canal treatment or dental extraction) due to the confusion between TN pain and dental pain (Table 1). To our knowledge, these results had not been reported in the literature yet.

Frequently, patients report that masticatory action triggers the pain and consequent weight loss; nevertheless, this relationship was not significant according to the Fisher test $(p=0.65)$. However, $36 \%$ of the patients did complain of weight loss related to TN pain.

A Kaplan-Meier survival curve (Graph 2) indicates that $80 \%$ of the patients are pain-free at 50 months after surgery without recurrence. This recurrence rate (20\%) indicates recurrence within up to 36 months and is in accordance with other series in the literature ${ }^{5,8-22}$. It is necessary to emphasize that, in longer follow-up periods, the recurrence rate usually becomes gradually higher. When $\mathrm{PBC}$ eventually fails or $\mathrm{TN}$ pain recurrences, $\mathrm{PBC}$ can be performed again in some cases. In our study, in spite of recurrence with other previous surgical treatments, there was not statistical difference between the improved and recurrence groups (Table 1) with TN. Consequently, according to our series, all patients may perform $\mathrm{PBC}$ and this criterion (previous surgical treatments) is not good to indicate which the patients are better to PBC or not.
Masticatory problems were an important postoperative complaint (18\%) and, according to others series, ipsilateral mastication weakness is temporary ${ }^{8,21,24,25}$. Subarachnoid hemorrhage may be a fatal complication, but in our study it spontaneously resolved ${ }^{26}$.

Some authors suggest that there is an association between $\mathrm{TN}$ and herpes simplex virus type 1, proposing as the primary cause of TN a single, active DNA sequence in genome of latent herpes simplex virus type $1^{19,27,28}$. In our study, 17 (43.6\%) patients had postoperative herpes simplex perioralis, however there was not statistical difference in the results (Table 1).

Only one patient was not pain-free after $\mathrm{PBC}$ in our study, and we observed that in this patient the balloon did not form a characteristic pear shape, an important factor for satisfactory results, suggesting that the balloon was not appropriately positioned on Gasser's ganglion. All of the other patients achieved pain relief: $80 \%$ had immediate pain relief and $18 \%$ had non-immediate relief. For the latter group, the mean time until complete pain relief was six days. Immediate pain relief is very common (about 90\%); however, total relief may be delayed by several days. Our good results of PBC have been confirmed in large series by other authors ${ }^{5,7,13,18,23}$.

Trigeminal neuralgia has a significant impact on the quality of life of the patients. During assessment of the patients with TN, care should be taken not to misdiagnose TN as dental pain leading the patients to undergo unnecessary dental procedures. $\mathrm{PBC}$ has been proposed as a great surgical option for the patients with TN in large published series. In our study, PBC was a safe and effective procedure with few adverse effects and no mortality. Despite being considered a side effect from PBC, the postoperative hypoesthesia was a prognostic factor to achieve a good result, and was well tolerated in most patients. PBC had high approval ratings, and was an important improving on patients' quality of life.

ACKNOWLEDGMENT - We gratefully thank Professor Roger Walz, MD, PhD, Division of Neurology, Federal University of Santa Catarina, for his help with the statistical analyses.

\section{REFERENCES}

1. Devor M, Amir R, Rappaport ZH. Pathophysiology of trigeminal neuralgia: the ignition hypothesis. Clin J Pain 2002;18:4-13.

2. Edlich RF, Winters KL, Britt L, Long WB $3^{\text {rd }}$. Trigeminal neuralgia. J Long Term Eff Med Implants 2006;16:185-192.

3. Kanpolat Y, Tatli M, Ugur HC, Kahilogullari G. Evaluation of platybasia in patients with idiopathic trigeminal neuralgia. Surg Neurol 2007;67:78-81.

4. Ishikawa M, Nishi S, Aoki T, et al. Operative findings in cases of trigeminal neuralgia without vascular compression: proposal of a different mechanism. J Clin Neurosci 2002;9:200-204

5. Lichtor T, Mullan JF. A 10-year follow-up review of percutaneous microcompression of the trigeminal ganglion. J Neurosurg 1990;72:49-54

6. Liu JK, Apfelbaum RI. Treatment of trigeminal neuralgia. Neurosurg Clin N Am 2004;15:319-334. 
7. Orlandini G. Choice of open or percutaneous procedures in the surgical treatment of trigeminal neuralgia. J Headache Pain 2002;3:37-47.

8. Belber CJ, Rak RA. Balloon compression rhizolysis in the surgical management of trigeminal neuralgia. Neurosurgery 1987;20:908-913.

9. Fraioli B, Esposito V, Guidetti B, Cruccu G, Manfredi M. Treatment of trigeminal neuralgia by thermocoagulation, glycerolization, and percutaneous compression of the gasserian ganglion and/or retrogasserian rootlets: long-term results and therapeutic protocol. Neurosurgery 1989; 24:239-245.

10. Lobato RD, Rivas JJ, Sarabia R, Lamas E. Percutaneous microcompression of the gasserian ganglion for trigeminal neuralgia. J Neurosurg 1990; 72:546-553

11. Abdennebi B, Amzar Y. [Treatment of essential trigeminal neuralgia by Gasserian compression using balloon (50 cases)]. Neurochirurgie 1991; 37:115-118.

12. Peragut JC, Gondin-Oliveira J, Fabrizi A, Sethian M. [Microcompression of Gasser's ganglion: a treatment of essential facial neuralgia. Apropos of 70 cases]. Neurochirurgie 1991;37:111-114.

13. Brown JA, McDaniel MD, Weaver MT. Percutaneous trigeminal nerve compression for treatment of trigeminal neuralgia: results in 50 patients. Neurosurgery 1993;32:570-573

14. Brown JA, Chittum CJ, Sabol D, Gouda JJ. Percutaneous balloon compression of the trigeminal nerve for treatment of trigeminal neuralgia. Neurosurg Focus 1996;1:e1-e4.

15. Brown JA. Direct carotid cavernous fistula after trigeminal balloon microcompression gangliolysis: case report. Neurosurgery 1997;40:886.

16. Abdennebi B, Mahfouf L, Nedjahi T. Long-term results of percutaneous compression of the gasserian ganglion in trigeminal neuralgia (series of 200 patients). Stereotact Funct Neurosurg 1997;68:190-195.

17. Brown JA, Gouda JJ. Percutaneous balloon compression of the trigeminal nerve. Neurosurg Clin N Am 1997:8:53-62.
18. Correa CF, Teixeira MJ. Balloon compression of the Gasserian ganglion for the treatment of trigeminal neuralgia. Stereotact Funct Neurosurg 1998;71:83-89.

19. Natarajan M. Percutaneous trigeminal ganglion balloon compression: experience in 40 patients. Neurol India 2000;48:330-332.

20. Skirving DJ, Dan NG. A 20-year review of percutaneous balloon compression of the trigeminal ganglion. J Neurosurg 2001;94:913-917.

21. Brown JA, Pilitsis JG. Percutaneous balloon compression for the treatment of trigeminal neuralgia: results in 56 patients based on balloon compression pressure monitoring. Neurosurg Focus 2005;18:e10.

22. Liu HB, Ma Y, Zou JJ, Li XG. Percutaneous microballoon compression for trigeminal neuralgia. Chin Med J (Engl) 2007;120:228-230.

23. Lopez BC, Hamlyn PJ, Zakrzewska JM. Systematic review of ablative neurosurgical techniques for the treatment of trigeminal neuralgia. Neurosurgery 2004;54:973-982.

24. Siqueira SR, Nobrega JC, Teixeira MJ, Siqueira JT. Masticatory problems after balloon compression for trigeminal neuralgia: a longitudinal study. J Oral Rehabil 2007;34:88-96.

25. Siqueira SR, Nobrega JC, Siqueira JT, Teixeira MJ. Frequency of postoperative complications after balloon compression for idiopathic trigeminal neuralgia: prospective study. Oral Surg Oral Med Oral Pathol Oral Radiol Endod 2006;102:e39-e45.

26. Spaziante R, Cappabianca P, Peca C, de Divitiis E. Subarachnoid hemorrhage and "normal pressure hydrocephalus": fatal complication of percutaneous microcompression of the gasserian ganglion. Case report. Neurosurgery 1988;22:148-151

27. Urculo E, Arrazola M, Gereka L, et al. [Evaluation of the Mullan's technique in the treatment of trigeminal neuralgia]. Rev Neurol 1998;27:477-484.

28. Ecker AD, Smith JE. Are latent, immediate-early genes of herpes simplex virus-1 essential in causing trigeminal neuralgia? Medical Hypotheses 2002:59:603-606 